\title{
A teoria fundamentada em dados aplicada ao campo da educação superior
}

\author{
Data based theory applied to the field of higher education \\ Teoría basada en datos aplicada al campo de la educación superior
}

Jardelina Bispo do Nascimento

ORCID: https://orcid.org/0000-0001-9421-1092

Universidade do Estado da Bahia, Brasil Universidade Federal da Bahia, Brasil E-mail: jardmmdc@gmail.com

Catarina Ferreira Silveira

ORCID: https://orcid.org/0000-0002-0684-0962 Instituto Federal de Educação, Ciência e Tecnologia da Bahia, Brasil Universidade Federal da Bahia, Brasil

E-mail: gestaocatarina@gmail.com

Hugo Saba Pereira Cardoso

ORCID: https://orcid.org/0000-0001-8402-6416

Universidade do Estado da Bahia, Brasil Centro Universitário SENAI CIMATEC, Brasil

E-mail: hugosaba@gmail.com

Eduardo Manoel Jorge de Freitas

ORCID: https://orcid.org/0000-0002-8597-5805

Universidade do Estado da Bahia, Brasil

E-mail: emjorge1974@gmail.com

\begin{abstract}
Resumo
Este artigo tem como objetivo apresentar como a Teoria Fundamentada em Dados (TFD) pode ser aplicada em pesquisas no campo da educação superior. A TFD é uma metodologia bastante utilizada na área de saúde, de administração, em psicologia e é reconhecida no cenário internacional. No Brasil, no campo da educação ela é pouca utilizada, e esse se torna o diferencial desta pesquisa. Surge assim, as seguintes questões: Que reflexões estão em evidências sobre a universidade na sociedade atual? Realizou-se uma pesquisa qualitativa exploratória tendo como metodologia a TFD construtivista e o uso dos softwares My-Sae e o Gephi para subsidiar a coleta e análise dos dados. Os resultados demonstram a utilidade da TFD na busca, análise e produção dos dados e categorias. A conclusão é que esta pode ser bastante útil se aplicada ao campo da educação, pois a sua finalidade é propositiva e reflexiva, além de ampliar o olhar nas questões do ensino superior.
\end{abstract}

Palavras-chave: Universidade; Educação superior; Teoria fundamentada em dados.

\begin{abstract}
This article aims to present how Grounded Theory (GT) can be applied in research in the field of higher education. GT is a methodology widely used in health, administration, and psychology, and is recognized on the international scene. In Brazil, in the field of education it is little used, and this becomes the differential of this research. Thus, the following questions arise What reflections are in evidence about the university in today's society? A qualitative exploratory research was carried out using as methodology the constructivist GT and the use of the software My-Sae and Gephi to support data collection and analysis. The results demonstrate the usefulness of GT in the search, analysis, and production of data and categories. The conclusion is that it can be quite useful if applied to the field of education, since its purpose is propositional and reflexive, besides broadening the view on higher education issues.
\end{abstract}

Keywords: University; Higher education; Data-founded theory.

\section{Resumen}

Este artículo pretende presentar cómo se puede aplicar la Teoría Fundamentada (TFD) en la investigación en el ámbito de la educación superior. La TFD es una metodología ampliamente utilizada en el ámbito de la salud, la administración y la psicología, y está reconocida en la escena internacional. En Brasil, en el campo de la educación es poco utilizado, y esto se convierte en el diferencial de esta investigación. Así, se plantean las siguientes cuestiones: ¿Qué reflexiones se hacen sobre la universidad en la sociedad actual? Se realizó una investigación cualitativa exploratoria teniendo como metodología el TFD constructivista y el uso de los softwares My-Sae y Gephi para subsidiar la recolección y el análisis de los datos. Los resultados muestran la utilidad del TFD en la búsqueda, análisis y producción de datos y categorías. La conclusión es que puede ser bastante útil si se aplica al campo de la educación, ya que su propósito es propositivo y reflexivo, además de ampliar la mirada sobre temas de educación superior.

Palabras clave: Universidad; Educación superior; Teoría basada en datos. 


\section{Introdução}

Que reflexões estão em evidências sobre a universidade na sociedade atual? Quais assuntos emergem nas produções sobre esta instituição milenar na contemporaneidade? Discutir sobre esse tema atualmente pode ser considerado redundante por definir como objeto uma instituição que se insere entre seus próprios objetos, mas também pelo volume de produções e estudos sobre ela (Fialho, 2011), tendo em vista que a universidade, como lócus do conhecimento vai requerer e provocar questionamentos, reflexões e novos outros (re)direcionamentos em função da sociedade que a cerca.

Em diferentes momentos da história pode-se constatar que a universidade adquiriu e desenvolveu vários sentidos na consolidação do saber, interferiu e interfere nos contextos, como também tem sido afetada por eles. Esta imbricação entre universidade e sociedade, sujeito e conhecimento, tem provocado expectativas e exigências cada vez maiores para que esta instituição amplie a sua capacidade de produzir conhecimentos que atendam ao contexto atual em todas as suas dimensões.

Este contexto é caracterizado pela celeridade e por mudanças impulsionadas pelas Tecnologias da Informação e Comunicação bem como pela globalização as quais têm afetado significativamente a forma de vida das pessoas, do e no planeta. Mais recentemente a pandemia do Covid-19 vêm impactando a humanidade em proporções antagônicas e inimagináveis. Antagônicas porque os reconhecidos benefícios das tecnologias e da ciência não foram eficazes em sugerir uma política que superasse a crise sanitária e climática mundial, como também porque assistiu-se a ciência encurralada entre a pane e a política econômica, dentre outros aspectos. Trata-se de um contexto em que a valorização da inovação e do conhecimento estão nas principais pautas nacionais e internacionais.

Diante desse cenário, este artigo tem como objetivo demonstrar como a Teoria Fundamentada em Dados (TFD) pode ser aplicada em uma pesquisa no campo da educação superior a qual buscou explorar os assuntos em evidências sobre a universidade na contemporaneidade. Trata-se de um estudo preliminar que se justifica por evidenciar os aspectos mais recorrentes sobre a universidade brasileira na atualidade presentes nos artigos científicos, por contribuir para a contextualização do tema, como também pela oportunidade de demonstrar a aplicação da metodologia da Teoria Fundamenta em Dados no campo da educação.

A Teoria Fundamentada em Dados (TFD) ou Grounded Theory (GT) terminologia original ou Teoria Fundamentada (TF), Teoria Embasada é conceituada como um método por alguns estudiosos (Tarozzi, 2011) (Charmar, 2009), ou metodologia sistemática, flexível, com diretrizes, fases e princípios. De modo geral, é um tipo de pesquisa qualitativa que gera ou pode gerar teorias através de dados, propriedades, categorias e conceitos (Strauss \& Corbin, 2008).

Esta metodologia é importante para o desenvolvimento de pesquisas a partir de dados empíricos e também por seu caráter exploratório. A escolha da Teoria Fundamentada Construtivista de adequa ao tipo a este estudo visto que é considerada como uma abordagem que capta a diversidade dos fatos, dos dados, informações e experiências do pesquisador captadas da realidade, além da multidimensionalidade, e multicausalidade dos fenômenos (Prigol \& Behrens, 2019).

O texto está organizado em quatro tópicos: o primeiro trata da metodologia de pesquisa adotada; o segundo tópico apresenta os resultados e discussão com uma breve abordagem sobre a TFD; a aplicação da TFD construtivista na pesquisa no campo da educação superior com o detalhamento das etapas, as técnicas e procedimentos da TFD no terceiro tópico e por fim, a conclusão.

\section{Metodologia}

A pesquisa qualitativa abrange diversas áreas de conhecimentos, entendimentos e métodos. Assim, para Oliveira (2011), a compreensão genérica do termo significa que a pesquisa qualitativa envolve atividades, ou a multiplicidade de investigação, consistindo em um conjunto de práticas materiais e interpretativas que dão visibilidade ao mundo através das representações criada por elas (Denzin \& Lincoln, 2006). 
Este trabalho é de caráter exploratório-descritivo, pois conforme Gill (2006) a pesquisa exploratória tem a finalidade de proporcionar a ampliação do conhecimento sobre determinado problema. Nesta perspectiva, o pesquisador busca conhecer melhor sobre o tema, faz um diagnóstico para assim obter e produzir a fundamentação e ou a documentação necessária e clara sobre o mesmo (Oliveira, 2011).

Na sequência Vergara (2006) sinaliza que pesquisa exploratória é realizada na área em que há pouco material acumulado e sistematizado, constituindo uma metodologia de busca. Assim, de acordo com a autora envolve também a pesquisa bibliográfica porque trata-se de um estudo sistematizado desenvolvido com base em material publicado (Carvalho, Duarte \& Souza, 2019)

As pesquisas exploratórias têm como principal característica o estudo e a construção de conhecimento sobre fenômenos, a fim de proporcionar uma melhor elucidação de ideias, o qual consequentemente permite a evidenciar o problema (Gill, 2006), (Oliveira, 2011). Neste sentido, o estudo sobre a aplicação da Metodologia da TFD no campo da educação superior tem a intenção de descrever e aplicar a referida metodologia na resolução do problema proposto.

A técnica utilizada para a coleta de dados foi a pesquisa bibliográfica com uso de software, metodologia da Teoria Fundamentada em Dados abordagem construtivista - TFD, tendo o memorando como background do presente artigo. A partir da amostragem inicial a exploração dos dados ocorreu mediante busca de artigos nos sites do Scopus, Mendeley e Publish or Perish, em seguida, utilizou-se os aplicativos My-Sae e o Gephi, respectivamente para as etapas de codificação e amostragem teórica.

A escolha do My-Sae foi importante para apoiar a técnica utilizada durante a coleta, análise e produção dos dados nos artigos, e o Gephi, para a codificação focalizada com os dados coletados designando as diversas categorias. Vale ressaltar o destaque do uso desses softwares numa pesquisa exploratória, os quais possibilitaram o acesso a um grande volume de dados, a obtenção, mineração e análise sistemática e ou semântica com mais praticidade e segurança na formulação das categorias.

O My-Sae - Semantic-Analysis Expert é um software desenvolvido por Lobato, Freitas e Saba (2018) com a finalidade de elaborar uma revisão sistemática de forma apurada, possibilitando a extração das informações e elementos dos artigos científicos selecionados, cruzamento de dados, bem como a formação de redes semânticas através dos termos mais relevantes em uma determinada área de pesquisa (Lobato, Freitas \& Saba, 2018). Patenteada e depositada no INPI (Instituto Nacional da Propriedade Industrial) com registro BR512019000987-8 em 21/05/2019 - Programa de Computador. Enquanto o Gephi é software utilizado para visualização, análise e manipulação de redes e grafos, tendo em sua base uma infinidade de nós, vértices e métricas para a análise de redes.

A próxima seção apresenta a execução do memorando referente a este estudo, etapa intermediária da TFD construtivista: um procedimento para a escrita e registro da coleta de dados, em que descrevemos as fases e etapas percorridas. Os memorandos são utilizados para anotações analíticas informais, ensaios, escritas sobre as construções dos códigos, categorias, como também possibilitam análises, reflexões, permitem o agrupamento de um grande volume de textos visto que os dados podem estar sem lapidar (Behrens e Prigoll, 2019). Por meio da redação dos memorandos se consegue distinguir as categorias das subcategorias, delinear o modo como elas estão relacionadas e enquadrá-la teoricamente (Charmaz, 2014).

Ainda no que concerne à metodologia da pesquisa qualitativa, Amado (2017) defende ser a abordagem mais apropriada para a investigação no campo da educação, uma vez que a especificidade do fenômeno educativo abrange variadas origens e natureza do e no campo global da ação humana. Para este autor, "a educação promove intencionalmente o desenvolvimento individual, social e cultural, na medida em que oferece a cada um ser humano um patrimônio" (Amado, 2017, p.315). 


\section{Resultados e Discussão}

O contexto atual tem sido marcado por mudanças nunca vivenciadas antes pela humanidade. A celeridade com que a produção a difusão das informações e do conhecimento vem ocorrendo na contemporaneidade tem impactado nas formas de pesquisar e de construir novos conhecimentos, na forma de ser e de viver das pessoas. Neste contexto, o pesquisador precisa adotar métodos e metodologias que retratem a realidade estudada, que ajudem a organizar seus pensamentos e ações para ampliar a compreensão sobre as relações, as novidades, as conexões encontradas durante a pesquisa.

Para responder as questões da pesquisa e atender ao objetivo proposto utilizou-se a Metodologia da Teoria Fundamentada em Dados Construtivista, a qual será apresentada a seguir em uma visão geral com o detalhamento das etapas para a obtenção dos dados.

\subsection{Aspectos gerais sobre a Teoria Fundamentada em Dados}

A Teoria Fundamentada em Dados (TFD) tem origem na década de 1960 em um contexto marcado por duas concepções diferentes de fazer e compreender a ciência: o positivismo e a fenomenologia interpretativista. Um período de fortes críticas ao método hipotético-dedutivo aplicado às Ciências Sociais e a descrença à pesquisa qualitativa (Nakayama et al., 2014).

Os autores Charmaz (2017) e Tarozzi (2011) citam que Barley Glasser e Anselm Strauss (1967) desenvolveram e defenderam o método indutivo para elaboração de teorias baseada em dados analisados e sistematizados e lançaram a Grounded Theory, ou a Teoria Fundamentada em Dados como um conjunto de procedimentos sistematizados capazes de gerar uma teoria fundada, ou embasada nos dados. Tratava-se de um novo método para a pesquisa qualitativa, construído sob dois conceitos: o primeiro, a comparação constante em que os dados são coletados e analisados simultaneamente e o segundo, a amostragem teórica - em que a definição de novos dados é determinada pela teoria que está sendo construída (Cepellos \& Tonelli, 2020).

Segundo Tarozzi (2011) no início da sua publicação a TFD recebeu variados e sucessivos entendimentos, inclusive dos seus criadores, originando outras correntes e posicionamentos. Destacam-se a vertente objetivista de tradição positivista que considera os dados como verdadeiros em si mesmo, uma vez que já existem e cabe ao pesquisador apenas encontrá-los e descobrir a teoria a partir deles (Cepellos \& Tonelli, 2020).

Denominada originalmente como Grounded Theory (GT), a TFD é conceituada como uma metodologia sistemática, flexível, com diretrizes, fases e princípios. De modo geral, é um tipo de pesquisa qualitativa que gera ou pode gerar teorias através de dados, propriedades, categorias e conceitos. A base desta metodologia está nos dados para elaboração de proposições e os aprendizados nascem dos dados e não de uma visão teórica pré-existente. O foco está na formulação de teorias ou proposições, que são as teorias substantivas, oriundas da coleta e análise dos dados (Charmaz, 2009) (Tarozzi, 2011).

É importante compreender que os sentidos dos dois termos: um de teorias e outro de dados. O objetivo da Teoria Fundamentada consiste em reunir dados empíricos para elaborar análises teóricas desde o início de um projeto. Os dados são construídos por meio de observações, das interações e dos materiais que são reunidos sobre o tópico ou sobre o ambiente, dos eventos e instituições. São a base da pesquisa e da teoria substantiva ou teorização que venha emergir dela. Charmaz (2009) citando Glaser e Strauss (1967) salientam que na TFD o conceito de dados é tudo, "tudo são dados". Na perspectiva construtivista, os dados são também os fenômenos sociais, pois vão além de elementos captados por qualquer tipo de pesquisa, mas são essencialmente construídos. A Teoria Fundamentada permite que, ao identificar os primeiros dados, convém separá-los, classificá-los e sintetizá-los por meio da codificação qualitativa.

A vertente da TFD construtivista preconizada por Charmaz (2017) defende que a "TFD serve como um modo de aprendizagem sobre os mundos que estudamos e como um método para a elaboração de teorias. Para a autora os dados e as teorias são construídos pelos pesquisadores e esses são partes do mundo e, portanto, compõem também os dados que coletam. 
Assim, as teorias são fundamentadas através das interações, dos movimentos das pessoas, das experiências dos pesquisadores e do ambiente.

Charmaz (2017), Prigoll e Behrens (2019), Copellos e Tonelli (2020) afirmam que a TFD construtivista tem como características os seguintes princípios e estrutura: pressupõe interação entre os sujeitos e o contexto no qual estão inseridos, demonstração das reflexões e identificação de como as interações e ações se desenvolveram durante o processo de pesquisa. Outro princípio é o trabalho simultâneo da interdependência e da sequência circular de todas as ações do processo de pesquisa, que favorece o conhecimento dos dados em ângulos diferentes, bem como a exploração de novas ideias sobre os dados, possibilitando ao pesquisador um direcionamento analítico.

A TFD construtivista proposta por Charmaz (2017) tem natureza exploratória o que possibilita a familiaridade do pesquisador com o problema, visto que pode ter uma relação direta com o objeto a ser estudado, visando torna-lo explícito e obter ideias e informações para uma investigação mais completa. É caracterizado com um método de pesquisa qualitativa, pois pode acrescentar novos dados que podem ser coletados de acordo com a necessidade da pesquisa. As suas diretrizes são flexíveis para permitir a circulação do pesquisador entre um foco mais amplo e mais aproximado dos dados coletados de forma a viabilizar o seu refinamento. Importante citar também que é estruturada das seguintes etapas: amostragem, inicial e teórica; codificação inicial e focalizada para a coleta e produção dos dados e o memorando, das quais serão descritas na seção seguinte, através da pesquisa exploratória realizada com os artigos. As buscas foram realizadas em seis fases e para cada uma delas constam uma figura ou tabela com os dados e os códigos.

\subsection{Aplicação da TFD construtivista na Pesquisa no campo da Educação Superior}

\subsubsection{Amostragem inicial}

A amostragem inicial é considerada como o ponto inicial por estabelecer os critérios, os locais ou sujeitos da pesquisa, as ferramentas adotadas na coleta e produção dos dados.

Nesta pesquisa a amostragem inicial é constituída pela expressão 'universidade e educação superior na contemporaneidade' uma categoria empírica ampla e que foi escolhida devido a relação e imbricação com a pesquisadora e as diretrizes da TFD. O objetivo, a metodologia e as técnicas adotadas compõem esta primeira fase e norteiam as seguintes.

Para a coleta e ou produção de dados a TFD utiliza as técnicas da etnografia, entrevista, observação, análise documental, textual e de outros métodos. Neste estudo, a técnica para a coleta de dados utilizada foi a análise textual, considerada nesta abordagem de pesquisa um modo de comunicação triangular no qual os envolvidos são o autor, o leitor e o texto dentro de um contexto (Prigoll \& Behrens 2019). Os textos utilizados na pesquisa são essenciais no processo de análise e produção dos dados e têm natureza diferentes.

Na TFD os textos são classificados como textos extraídos e textos existentes. Segundo Charmaz (2014) os textos extraídos são aqueles produzidos pelos participantes da pesquisa, através das transcrições das respostas de questionários, de entrevistas, anotações, observações do pesquisador. São textos extraídos e produzidos diretamente pelo pesquisador.

Os textos existentes, conforme a TFD são os documentos diversos que não foram produzidos pelo pesquisador como relatórios, registros, documentos, publicações ou privadas, que são considerados fonte de dados secundários ou suplementares. $\mathrm{Na}$ análise textual, é necessário haver um processo de tradução e desconstrução por meio dos elementos analíticos para identificar relações entre as partes e o todo dos dados coletados e vice-versa (Prigoll \& Behrens 2019). Por essa razão, essa metodologia é vista como uma ação circular. 


\subsubsection{Codificação Inicial - primeira fase de coleta e análise de dados}

Nesta primeira fase de coleta foram realizadas buscas nas bases de dados do Mendeley, Scopus e Plublish or Perish tendo como amostragem a expressão: 'Universidade e Ensino Superior na contemporaneidade' período: 2001 a 2020. Essas buscas ocorreram em novembro e dezembro de 2020. Os dados foram explorados em artigos científicos, a partir dos seguintes critérios: artigos revisados por pares, idioma português. Considerando que alguns artigos se repetiam entre as três bases de dados citadas, optou-se pela base do Mendeley pela sua interface com outras bases, bem como pela aplicabilidade com os softwares My-Sae e o Gephi.

O Mendeley é um software gerenciador de documentos, da literatura e acervo bibliográfico publicada em todo o mundo. Lobato, Freitas e Saba (2018) salientam no manual da patente, que o Mendeley é propício para o compartilhamento dos arquivos pela internet, permitindo a colaboração na organização, armazenamento e recuperação dos documentos, e assim apresenta a melhor cobertura e interação com o My-Sae. Nesta pesquisa, esses softwares se destacam nas fases da TFD, na codificação inicial, focalizada, axial e na amostragem teórica.

O estabelecimento do período de busca entre os anos de 2001 a 2020, se justifica por demarcar a contemporaneidade, com o século XXI, bem como para ter a noção das discussões e ou assuntos emergentes sobre a universidade. Das buscas realizadas no Mendeley, 6.264 artigos foram encontrados e selecionados para serem exportados e analisados no My-Sae, conforme Figura 1. A codificação inicial é considerada mais genérica, pode ser realizada palavra por palavra, mais utilizada nas pesquisas documentais e textuais, como é o caso aplicado. A próxima etapa, refina e categoriza os dados.

Figura 1. Plataforma de busca do Mendeley.

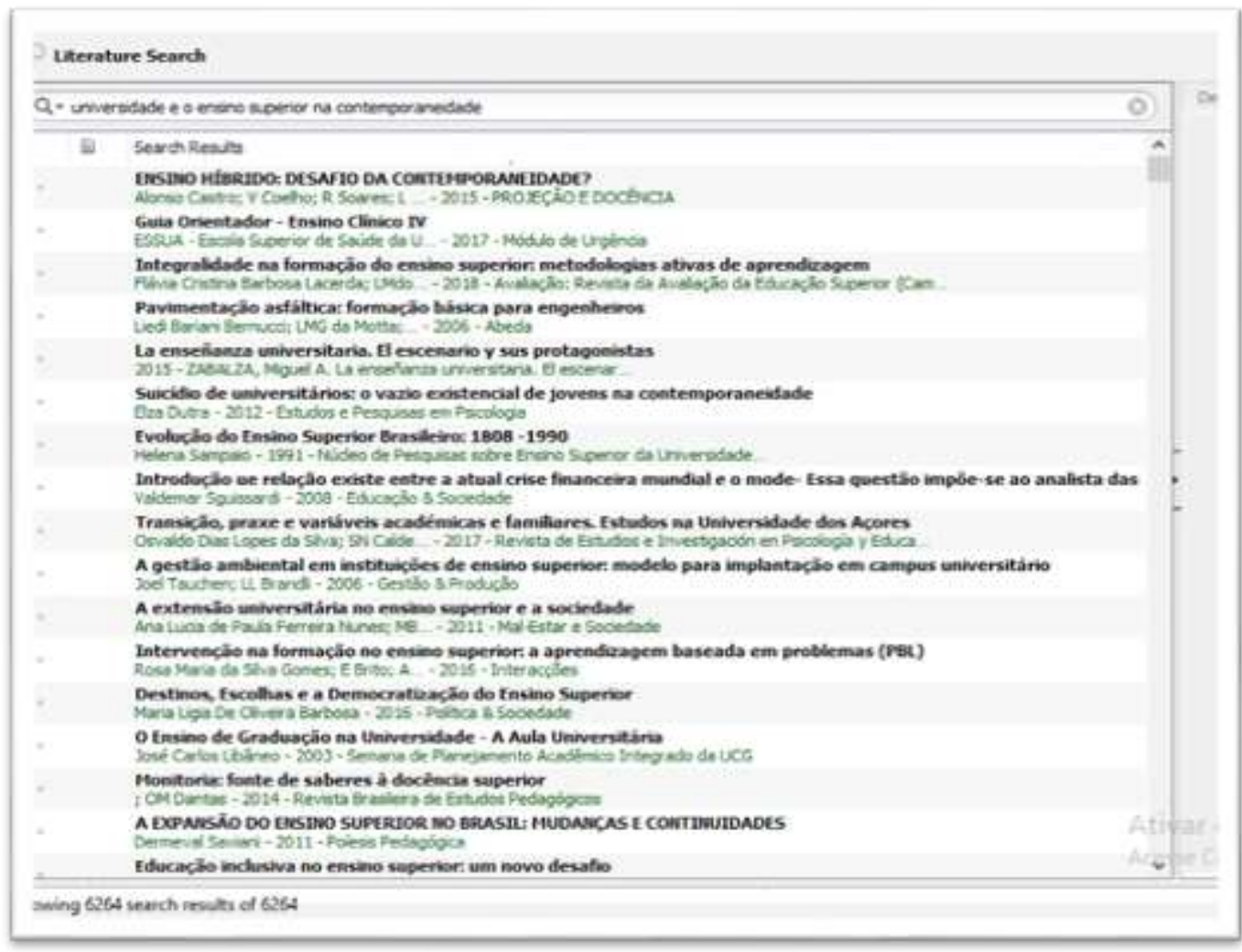

Fonte: Autores. 
Figura 2. Plataforma do My-Sae com os dados cruzados - área interdisciplinar.

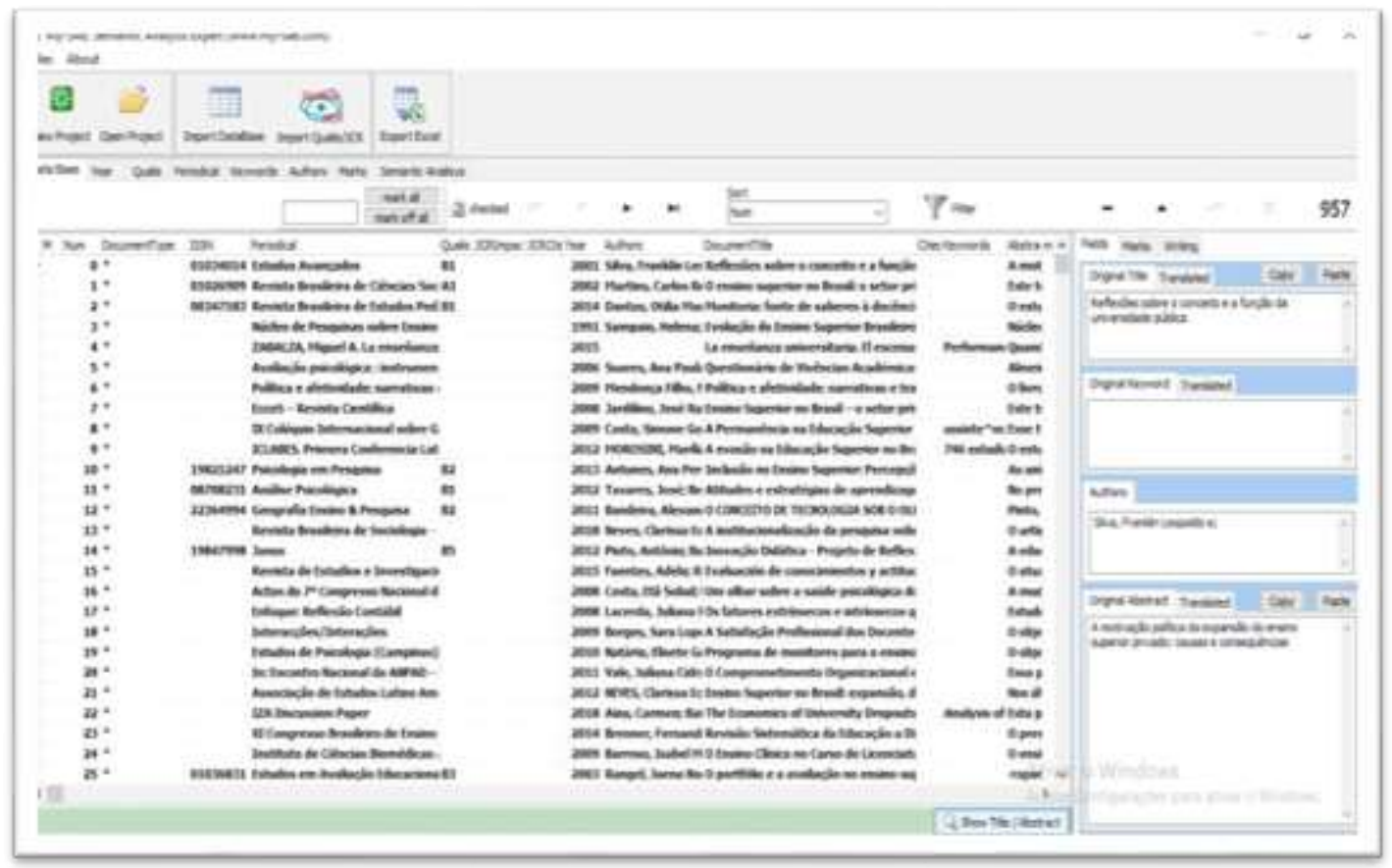

Fonte: Autores.

A Figura 1 apresenta o total de publicação sobre o tema pesquisado na plataforma do Mendeley, realizadas nos meses de novembro e dezembro de 2020 e repetido em janeiro de 2021. Após a seleção de todos os artigos estes foram exportados para o My-Sae para a criação de um novo projeto contendo os dados, ou seja, os artigos que originaram os dados iniciais, conforme Figura 2.

Os 6.264 artigos apresentados na Figura 1 foram exportados para o My-Sae para classificação e análise dos dados. Após os dados incorporados foi feito o cruzamento com a base Qualis, área interdisciplinar, período 2001 a 2020, obtendo-se 957 artigos conforme a Figura 2.

Na Teoria Fundamentada nesta etapa é densa, permite liberdade ao pesquisador para incluir e ou excluir mais elementos, de forma que o volume de dados capturados nesta fase possa ser refinado na fase seguinte e gerar categorias e subcategorias que possam dar conta da questão de pesquisa e dos objetivos.

Observa-se na Figura 2 o quantitativo de documentos, informações relevantes dos dados como ano, autores, palavraschaves, impacto, periódicos, ou seja, elementos para a etapa da análise dos dados.

Segundo Lobato, Freitas e Saba (2018), após pesquisar os documentos científicos pelo Mendeley exportar esses dados no formato indicado, para o SAE e cruzar com os dados do Qualis e JCR, a base de dados está pronta para ser analisada. Para analisar os dados, a plataforma do SAE apresenta as informações em forma de tabela de cada publicação como ano, classificação qualis, periódicos, palavras chaves utilizadas e Autores/co-autores conforme figura 3.

Para a fase de análise dos dados no My-Sae, Figura 3. Foi acessada a aba de palavras-chaves, depois, a aba análise semântica e a extração foi realizada no abstract. Neste campo foi excluído os termos repetidos, bem como outros idiomas que não fosse o português. Foi necessário refinar, filtrar esses dados para obter novos códigos, palavras, frases que tenham condição de categoria.

Com o propósito de refinar esses dados e identificar os códigos ou palavras evidentes, estes foram exportados para o Gephi gerando um grafo Figura 4 - nuvem de palavras, apresentando, assim, os códigos emergentes. 
Figura 3. Plataforma do My-Sae análise dos dados.

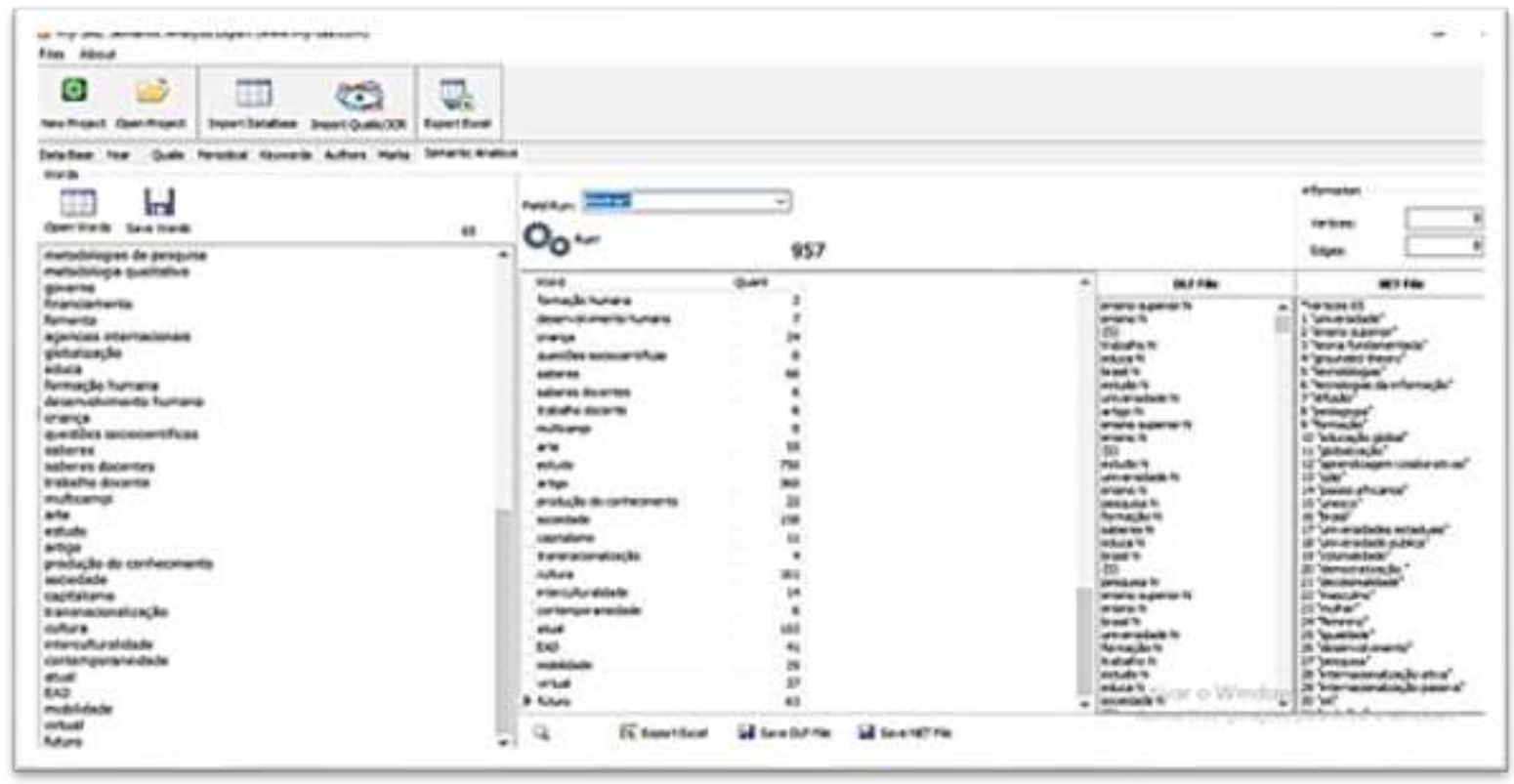

Fonte: Autores.

Figura 4. Nuvem de palavras formado pelo Gephi.

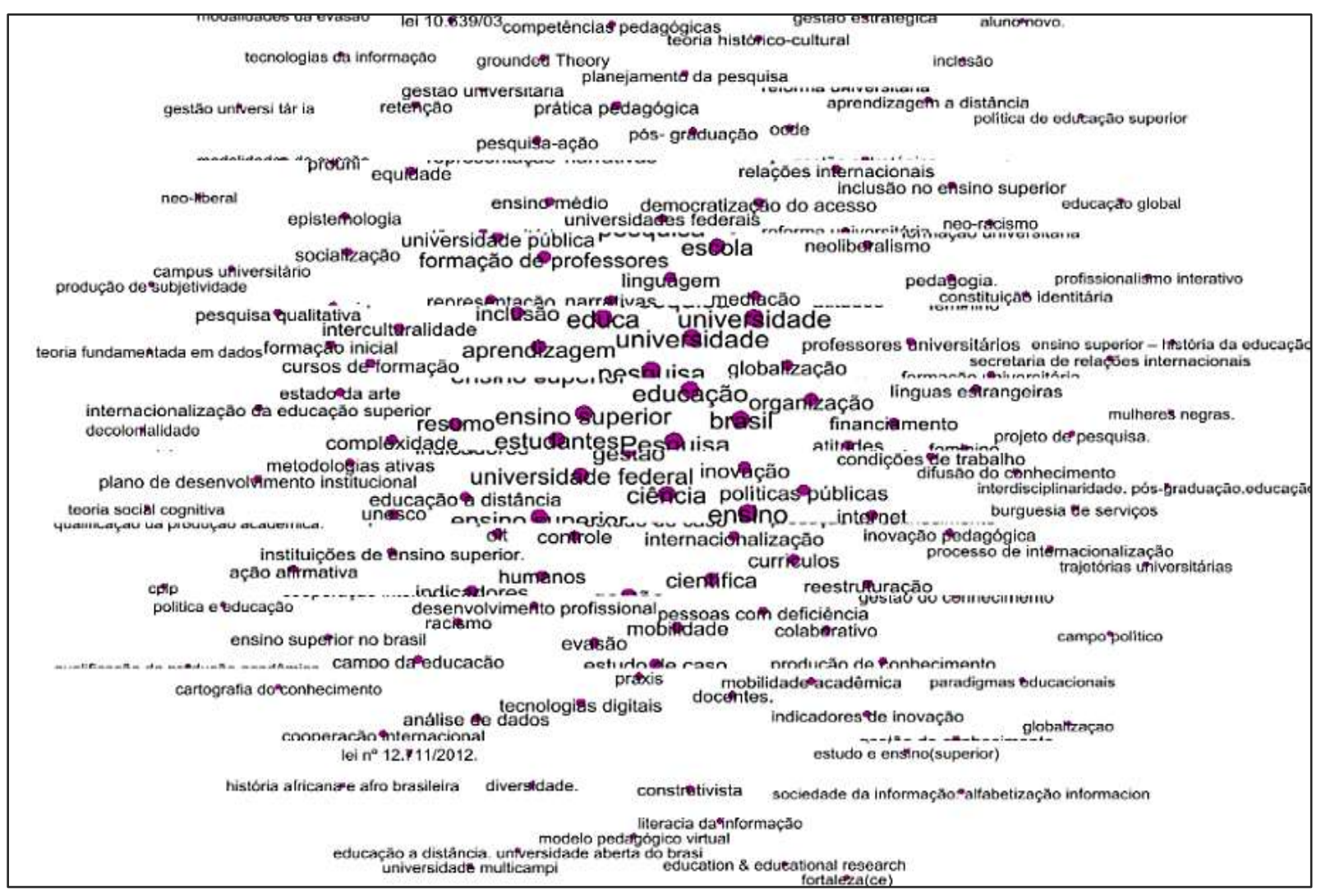

Fonte: Autores.

A variação de tamanhos dos rótulos cor de rosa representa a dimensão dos códigos, ou seja, são os mais repetidos nos resumos e presentes em todas as fases de busca. Estes códigos apresentados na Figura 4, compõe a codificação inicial e foram refinados em novas etapas da codificação focalizada e na amostragem teórica a seguir. 


\subsubsection{Codificação focalizada}

Esta etapa da TFD construtivista, comporta os materiais obtidos na codificação inicial, é a fase em que o pesquisador utiliza os códigos já mapeados da codificação anterior fazendo uma rigorosa avaliação para selecionar os mais significativos, os que mais se repetem, os que possibilitam uma melhor compreensão analítica, para categorizar os dados de forma completa (Prigoll e Behrens 2019). A codificação focalizada permite o retorno à codificação inicial, a inclusão de novos critérios, de forma a transformar os códigos em categorias e delimitá-las na amostragem teórica (Cepellos \& Tonelli 2020). Nesta fase, foram acrescidas novas buscas com os termos Teoria Fundamentada em Dados e Brasil.

Figura 5. Mendeley - Nova busca para a codificação focalizada.

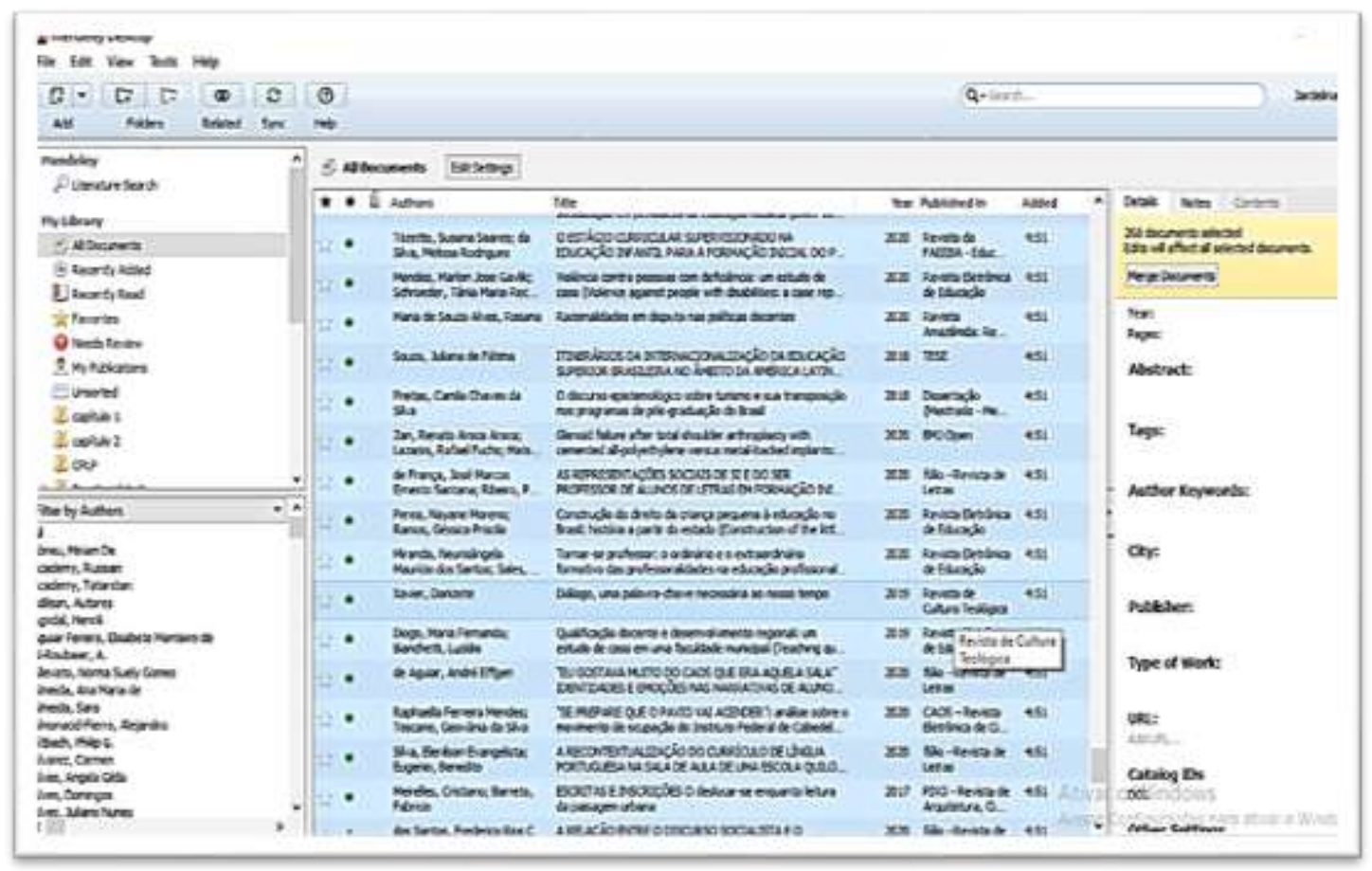

Fonte: Autores.

Para o desenvolvimento da codificação focalizada utilizou-se os códigos obtidos na codificação inicial, acrescentandose novos critérios no Mendeley: alterou-se o período de 2017 a 2021, obtendo-se 268 artigos conforme Figura 5. A justificativa para esta alteração deve-se à necessidade de refinar o processo de coleta de dados. Esta delimitação do tempo e local é também parte de um procedimento da codificação axial.

Os 268 artigos foram enviados para o My-Sae para serem cruzados, comparados conforme a fFigura 5. Os dados repetidos foram excluídos na figura abaixo 6. Na codificação focalizada faz-se os ajustes para a identificação das categorias com a perspectiva de avançar para a amostragem teórica.

A redefinição e análise desses 268 dados, resultaram em 219 códigos, dos quais foram refinados no Gephi conforme a rede semântica produzida na Figura 7. As palavras em negrito e com os nós (os pontos cor de laranja e as palavras maiores) representam os códigos mais repetidos nos resumos dos artigos e estão também interconectados, representados pelas linhas verdes o que significa que esses códigos interagem entre si em diferentes proporções e que essa relação pode ocorrer no mesmo artigo e ou em artigos diferentes. 
Figura 6. Redefinição de dados e período no My-Sae.

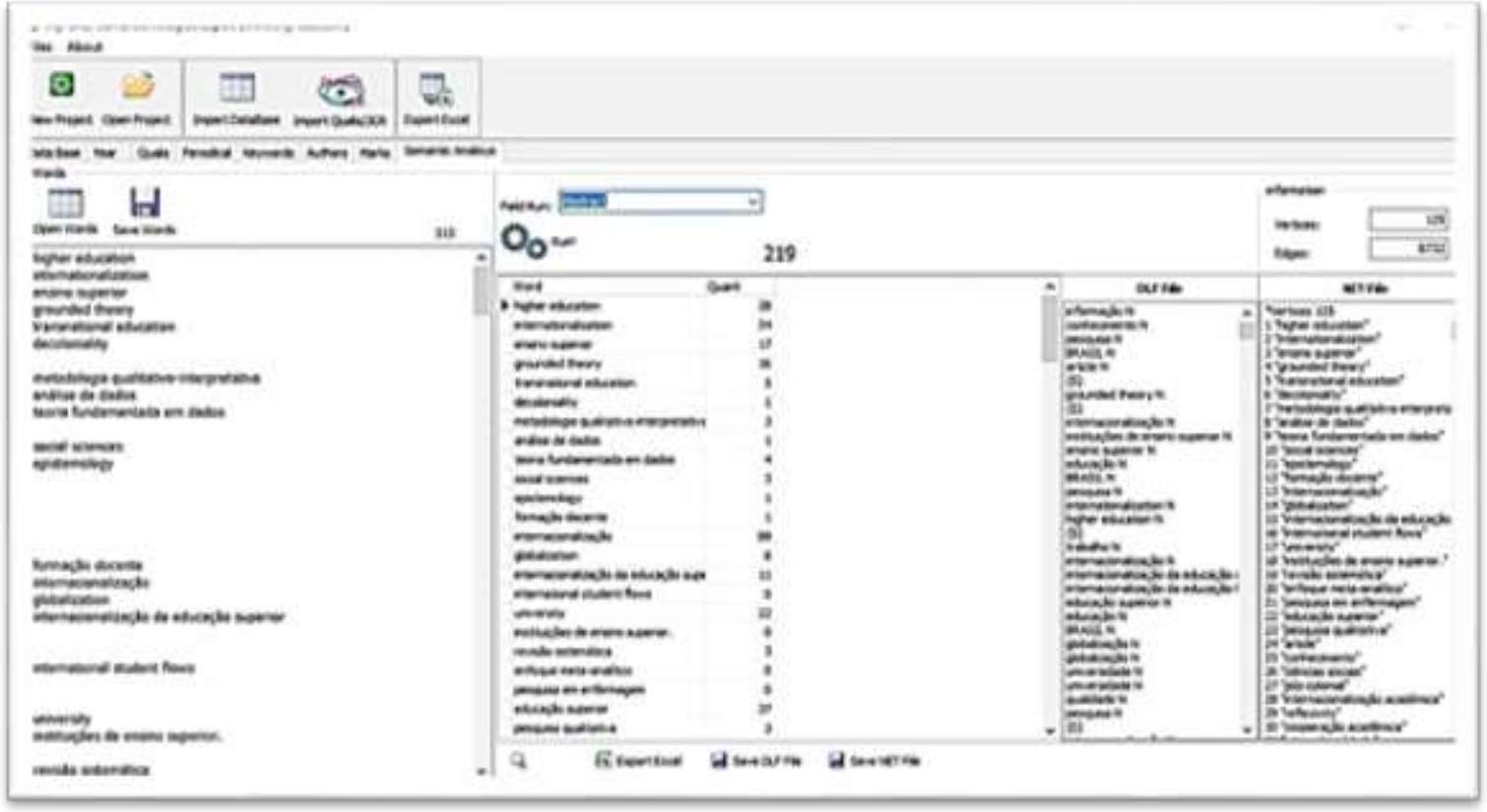

Fonte: Autores.

Segundo Charmaz (2009) os dados coletados transformados em códigos precisam ser avaliados sistematicamente. Pois dos códigos desenvolvem-se as categorias que demonstram as ações, ou assunto, ou a experiência. As categorias têm a função de explicitar pensamentos e concepções dos dados. Possuem pontos, questões e organizações que podem ser encontrados em outros códigos. Ou seja, podem emergir da reprodução da fala em uma entrevista ou em fragmentos de um texto, uma palavra ou resumo de uma definição teórica (Prigoll e Behrens, 2019). Neste estudo os códigos foram obtidos dos resumos dos artigos.

Figura 7. códigos identificados em categorias e subcategorias.

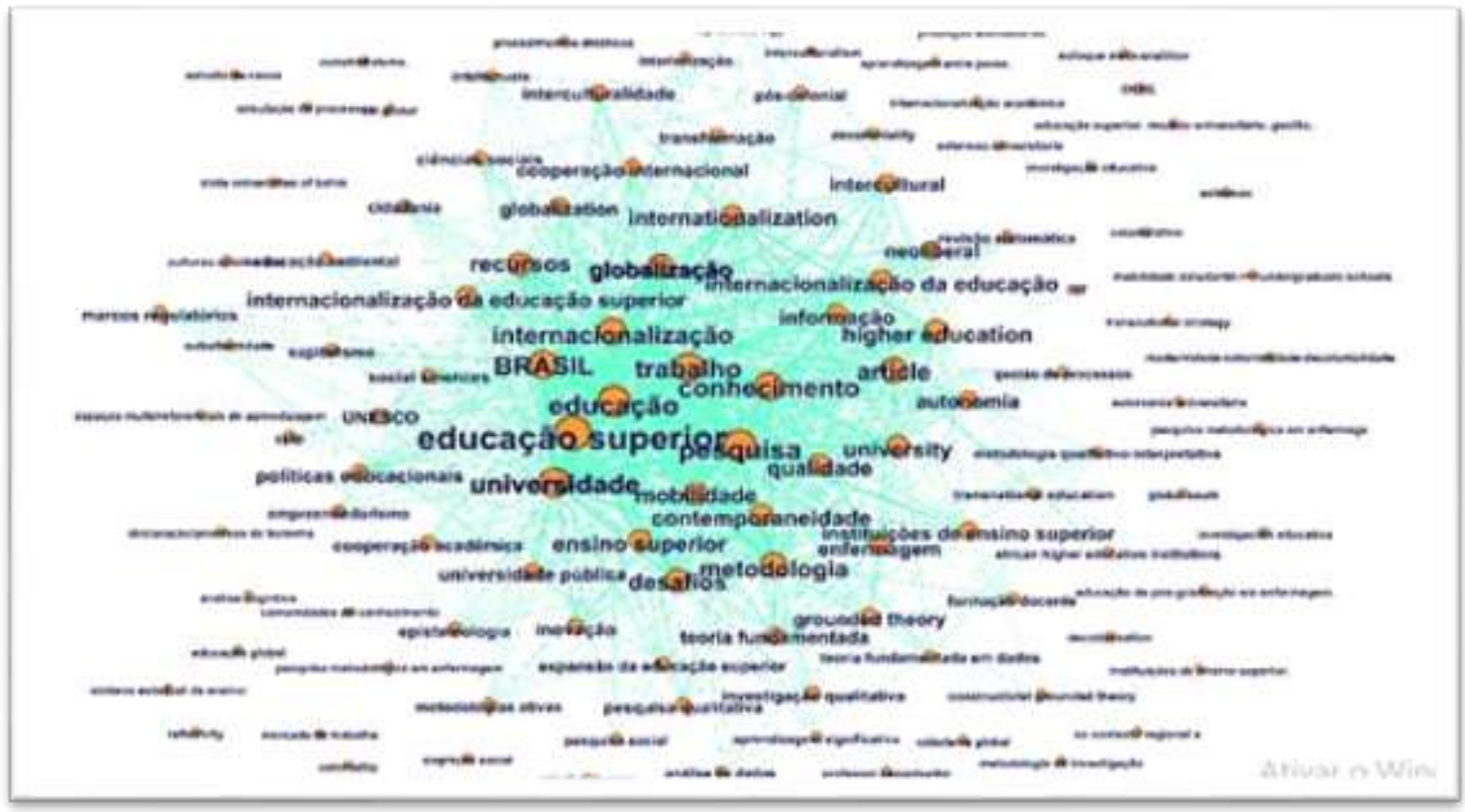

Fonte: Autores. 
Junto com os códigos evidenciados na Figura 7, as seguintes reflexões contribuíram para a definição das categorias: quais desses códigos respondem as questões norteadoras? Os procedimentos de buscas atenderam na produção dos dados? Os dados refinados têm se repetido?

O Quadro 1 representa as etapas e fases percorridas durante a pesquisa. Percebe-se que os códigos se repetem e se saturam e servirão para subsidiar a amostragem teórica. Esta etapa da TFD consiste em orientar o pesquisador no percurso para buscar o refinamento e obter dados para explicar as categorias e subcategorias dentro de um desenvolvimento conceitual e teórico, abordado nesta discussão.

Quadro 1. Etapas percorridas da TFD.

\begin{tabular}{|c|c|c|}
\hline ETAPAS DA TFD & FASES DA PESQUISA & CÓDIGOS ENCONTRADOS \\
\hline $\begin{array}{l}\text { AMOSTRAGEM } \\
\text { INICIAL }\end{array}$ & $\begin{array}{l}\text { - Definição da categoria principal: tema, } \\
\text { - Questão central e objetivos } \\
\text { - Definição das bases de dados }\end{array}$ & $\begin{array}{l}\text { Códigos a serem pesquisados. Palavras- } \\
\text { chaves: Universidade, ensino superior e } \\
\text { contemporaneidade. }\end{array}$ \\
\hline $\begin{array}{l}\text { CODIFICAÇÃO } \\
\text { INICIAL }\end{array}$ & $\begin{array}{l}\text { - Fase I - busca das palavras-chaves nas bases } \\
\text { de dados Capes, Scoppus e Mendeley. } \\
\text { Definição da base Mendeley. } \\
\text { - Fase II - Busca no Mendeley, exploração dos } \\
\text { artigos: Exportação para o My-Sae. } \\
\text { - Fase III - Tratamento dos dados no My-Sae } \\
\text { para classificar, categorizar e refinar os dados; } \\
\text { - Fase IV Gephi para minerar e representar os } \\
\text { códigos. }\end{array}$ & $\begin{array}{l}\text { Universidade, universidade pública, ensino } \\
\text { superior, educação, educação básica, } \\
\text { currículo, educação a distância, educa, } \\
\text { pesquisa inclusão, interculturalidade, ensino, } \\
\text { Brasil; internacionalização; mobilidade, } \\
\text { complexidade; humano, política educacional } \\
\text { mulher, democratização; gestão; ciência; } \\
\text { tecnologias }\end{array}$ \\
\hline \multirow{3}{*}{$\begin{array}{l}\text { CODIFICAÇÃO } \\
\text { FOCALIZADA }\end{array}$} & $\begin{array}{l}\text { Retorno à fase I e II da codificação inicial, } \\
\text { definição de novos critérios: palavras e período. } \\
\text { - Fase I - nova pesquisa no Mendeley período e } \\
\text { inclusão do termo TFD; }\end{array}$ & \multirow{3}{*}{$\begin{array}{l}\text { Universidade, ensino superior; educação } \\
\text { superior; pesquisa; globalização; trabalho, } \\
\text { gestão internacionalização; Brasil } \\
\text { decolonialidade e colonialidade } \\
\text { contemporaneidade; autonomia } \\
\text { Grounded Theory; metodologia } \\
\text { Conhecimento; recursos; informação; }\end{array}$} \\
\hline & $\begin{array}{l}\text { - Fase II - My-Sae: inclusão de novos códigos - } \\
\text { refinação }\end{array}$ & \\
\hline & $\begin{array}{l}\text { - Fase III - Gephi, nova representação formação } \\
\text { das categorias - identificação dos termos repetidos } \\
\text { e robustos. }\end{array}$ & \\
\hline
\end{tabular}

Fonte: Autores.

Para Charmaz (2009) codificar significa associar marcadores e segmentos de dados que representam aquilo de que se trata cada um dos segmentos. A codificação refina os dados, classifica-os e fornece um instrumento para que se possam estabelecer comparações com outros elementos e dados. Ao estabelecer e codificar numerosas comparações a compreensão analítica dos dados começa a tomar forma. Faz-se necessário a redação e as anotações analíticas preliminares sobre códigos e comparações, bem como qualquer outra ideia que apareça sobre os dados, na fase intermediária denominada memorando.

Neste estudo, os códigos são as palavras encontradas nas fases da codificação inicial e focalizada, as quais tem a dimensão de categorias e subcategorias, em função do seu grau de interação e repetição nas buscas conforme as Figuras 4 e 7 .

\subsubsection{Amostragem teórica}

A amostragem teórica da TFD é uma etapa estratégica que ocorre durante a pesquisa, possibilita avançar ou recuar na coleta de dados, busca saber junto com a codificação axial, onde e quando foi realizada a pesquisa com vistas a encontrar mais dados que possam completar lacunas e que possibilitem entender a dinâmica de determinado processo. É uma lógica de 
comparação constante. Tem como objetivo buscar e reunir dados pertinentes para elaborar e refinar as categorias emergentes. (Charmaz 2014) (Prigol \& Behrens 2019).

Neste estudo a comparação foi realizada desde a amostragem inicial: comparação dos sítios de buscas como o portal de Periódicos da Capes, a Publish or Perish, a Scopus e o Mendeley, optando-se pelo último. Os dados e os códigos foram comparados ao longo da codificação e refinados de acordo com as suas dimensões verificadas nas repetições.

\subsubsection{Memorando}

Memorandos são textos, anotações, registros de pesquisa que se estruturam paulatinamente ao longo do processo de codificação dos dados, esboça ideias e inicia uma discussão entre elas contém as histórias Charmaz (2009, p. 108 e 109); os dados, podem ser ampliados, aprofundados, ao longo do processo ou podem ser organizados e arquivados, conservando e mantendo suas estruturas iniciais, na forma de versões sequenciais. Neste processo, conceitos e categorias emergem e são organizados para aprofundamentos, antes da produção de memorandos avançados e do Relatório ou da Teorização, no final da pesquisa.

Também de acordo com Charmaz (2017) na sistematização da Teoria Fundamentada Construtivista (TFD), os memorandos são classificados em iniciais e avançados. São considerados como a espinha dorsal da produção, pois eles vão tomando "corporificação" e organização desde os primeiros dados até a consolidação do conjunto de memorandos na forma do Relatório Final. Essa classificação dos memorandos consiste na organização lógica construídos na pesquisa. Requer três ações: (i) nome do memorando, descrição de seu conteúdo e abrangência. (ii) representação gráfica; (iii) integração à pesquisa. Essa integração dos memorandos envolve a organização prévia dos relatórios, que farão parte da redação do relatório final com a apresentação da teorização.

\subsubsection{Operacionalizando a TFD construtivista}

Uma das características da TFD é ser considerada como uma metodologia sistemática. Assim, o desenvolvimento da pesquisa inicia-se a partir de quatro etapas: a primeira, a definição da área de estudo e a questão de pesquisa, formulação de uma pergunta ampla. Essa amplitude apoia o método para a coleta dos dados emergentes podendo surgir da etnografia, a entrevista, e a técnica da análise de textos existentes ou extraídos - acrescidas dos procedimentos da análise documental e fundamentação teórica a bibliográfica. Com vista a alcançar o critério de qualidade, credibilidade e profundidade, novos dados deverão ser coletados através de outras fontes como a aplicação de questionários, de entrevistas, da observação, o registro da observação e da comparação com os dados oriundos de textos (Charmaz, 2017).

Depois a análise e comparação dos dados, delineamento de como os dados relevantes são coletados; definição do tipo de coleta de dados, comparação os dados relevantes.

Após a coleta dos dados que antecedeu a definição do tema, do problema, o método de coleta de dados, a TFD construtivista sugere os seguintes procedimentos para tratar, analisar e produzir os dados:

a) A codificação inicial consiste em categorizar, essa etapa ocorre após a coleta dos dados, deve ser bastante organizada abrangente. É o momento de codificá-los, enumerar cada dado coletado e organizar, a partir de fragmento do texto ou documento originário dos dados coletados. Nessa codificação inicial os dados podem ser agrupados e codificados individualmente visando a elaboração do memorando inicial.

b) Redação dos Memorandos Iniciais: São pequenos textos com a codificação inicial dos dados. Eles vão se estruturando ao longo do processo, podem ser ampliados, aprofundados, organizados e arquivados, mas devem manter as suas estruturas iniciais. 
Aqui, os conceitos e categorias emergem e são organizados para as próximas etapas, como o memorando avançado e o relatório final da teorização. Os memorandos iniciais ficam a critério da criatividade do pesquisador, até as últimas escritas.

c) Codificação focalizada: para Charmaz (2017) essa é a segunda fase principal da codificação dá sequência à codificação inicial aprofundando-a, com explicações maiores sobre os dados. Codificação focalizada significa utilizar os códigos anteriores mais significativos ou frequentes, para analisar minuciosamente grande quantidade de dados. É o momento de tomada de decisões sobre quais os códigos iniciais permitem uma compreensão analítica para uma categoria. Charmaz (2017) a autora também se refere a essa codificação como ou codificação saturada, o sentido aqui é de exame, de avaliação para verificar vestígios sobre o assunto, de saturação.

d) Codificação Axial: trata-se de uma codificação defendida por Strauss e Corbin (1998), para relacionar as categorias principais às subcategorias. Aqui se especifica as dimensões e as propriedades de uma categoria. Ela estrutura as relações entre as categorias e subcategorias em que a categoria central é capilarizada pelas categorias outras, de forma interligadas, e questiona o modo como elas estão relacionadas. Esta fase é marcada pela amplitude do tema e do texto, uma retomada para recompor todos os dados novamente de forma coerente.

e) Redação dos Memorandos Avançados é a fase determinante para a teorização. Aqui os memorandos iniciais se expandem, as categorias agrupadas compõem os conceitos e as discussões construídas através das abstrações, das leituras e criatividade do autor.

f) Amostragem teórica: segundo Charmaz (2014) essa é a fase de testar a originalidade, de esclarecer e ajuda a explicar os conceitos. Aqui ocorre a codificação teórica. Para a autora, os códigos teóricos especificam as relações possíveis entre as categorias desenvolvidas e a codificação focalizada. Esses códigos são integrativos, podem ajudar a produzir a escrita de forma coerente e consistente. Eles não apenas conceituam o modo como os códigos estão relacionados, como alteram a história analítico para uma orientação teórica.

A TFD é uma metodologia de pesquisa qualitativa, estruturada, sistemática, flexível e as suas fases muitas vezes se sobrepõe umas às outras, seu método se baseia na comparação, análise, construção e produção de dados. A sua dinâmica expressa nas fases de coleta e análise de dados delineiam a amostragem teórica de maneira que a resposta à pergunta de pesquisa vá tomando forma e se configure com a última fase da codificação teórica. Os códigos teóricos são integrativos, tem a finalidade de formar um texto analítico, coerente especificando as relações possíveis entre as categorias desenvolvidas durante a codificação focalizada (Prigol e Behrens, 2019).

Segundo Charmaz (2017), a codificação teórica fornece ao pesquisador a lógica para organizar a sua análise e um caminho para a criação das conexões formadas pelos códigos teóricos, ou pelas categorias conforme mencionados na discussão.

\subsubsection{Aspectos sobre a Universidade na contemporaneidade}

Ao abordar a temática educação superior: universidade e o projeto de formação cidadã, Morosini \& Fernandes (2011) apresentam vários elementos, ou melhor, dados, que colaboram na resposta à reflexão inicial desse artigo. Salientam que a discussão sobre a universidade implica em inserir a sociedade e o seu entorno, na medida em que os problemas da universidade não se referem somente à sua constituição e desenvolvimento, mas a um cenário mais amplo da educação superior.

A relação teórico prática está presente em diversos âmbitos da sociedade e essa dicotomia também é visível no campo da educação (Silveira, 2018). Essa autora apresenta uma discussão importante na contemporaneidade referente a interação universidade-empresa (Silveira, Nascimento \& Saba, 2020).

Em Morosini e Fernandes (2011), destacou-se os seguintes códigos: educação superior; internacionalização, sociedade do conhecimento, globalização, formação cidadã; ensino, pesquisa e extensão, tecnologias que se repetiram em outros artigos. 
Na sequência, Canan e Sudbrack (2018) apresentam uma discussão contemporânea sobre a educação superior no território Íbero-Americano destacando os aspectos históricos da universidade brasileira e da política de educação superior, as fragilidades com que chegam ao século XXI e as condições em que se encontram na globalização neoliberal.

Salientam os autores que para recuperar-se com o mundo do trabalho há exigências epistemológica, diálogo com a sociedade, inclusão, construção e fortalecimento das utopias, pela singularidade e a interferência dos organismos internacionais (Canan \& Sudbrack, 2018, p. 339).

Ao abordar a transição da universidade do século XX para o XXI (Santos, 2010), aponta elementos relevantes para essa discussão: desde a identificação das crises passadas pela universidade, aos desafios impostos pela globalização: aqui destacamos as tecnologias da informação e da comunicação, transnacionalização do mercado universitário, a educação a Distância. Ainda segundo esse autor único modo eficaz e emancipatório de enfrentar a globalização neoliberal é contrapor uma globalização alternativa, contra-hegemônica. Em resposta, ele sugere uma proposta democrática e emancipatória de universidade, que possa atender e responder as demandas sociais.

Conforme a metodologia e a perspectiva da TFD construtivista, os resultados obtidos podem ser agrupados em dois grupos: o primeiro, relativo à resposta da questão, a partir da experiência e realidade do pesquisador; e o segundo resultado das buscas, para finalmente proceder-se à análise inicial dos principais achados relacionados ao tema proposto.

Neste artigo os resultados foram agrupados para responder à questão da pesquisa em seguida, distribuídos no texto respectivamente. Os códigos: Universidade; autonomia, conceitos e história da universidade; educação superior; Globalização; Sociedade do conhecimento; tecnologias; Internacionalização; ensino, pesquisa e extensão; Formação, dentre outros elementos.

Dos artigos analisados a partir do TFD, vale destacar dois estudos que apresentam o estado da arte em dois aspectos: o primeiro sobre a produção científica brasileira entre o período de 2008 a 2012, de Torres et al. (2014) e Gonçalves (2016) em que aborda o uso da metodologia nos anos de 2014 a 2016. O primeiro aborda os conceitos e as correntes da Grounded Theory, identificou, ao longo de 27 meses esta abordagem em 278 artigos, teses e dissertações. O segundo autor, abordou o cenário da GT e as bases epistemológicas, salientando a contribuição dessa metodologia no movimento dialético constante. Ressalta-se também as discussões nos textos sob a contribuição de Bandeira-de-Mello et al. (2018) em que trata da operacionalização do método da GT nas pesquisas, as técnicas e procedimentos de análise e o uso de software ATLAS/TI como suporte e estratégia para refinar os dados.

Conforme aponta Fialho (2011) a universidade oferece e oferece-se em um arco temático de inesgotável riqueza à investigação científica, com muitas regiões inexploradas, fazendo parte de uma vasta produção sobre si e sobre todos os outros conhecimentos. Neste sentido, a TFD se apresenta como um método ou metodologia capaz de dar conta nas suas devidas áreas e proporções das investigações acerca da universidade, visto que é necessário compreendê-la na sua grandeza, nos seus limites e recusas.

Ainda segundo Fialho (2011), o campo de estudos sobre a universidade é muito amplo, com uma multiplicidade de sentidos, que varia de acordo com os contextos social, político e econômico. No Brasil, embora a universidade tenha surgido tardiamente em relação à outras nações, este campo se impõe de forma vasta e diversificada e as discussões atualmente tem sido em torno das questões contemporâneas já mencionadas acima.

\section{Conclusão}

O objetivo desse estudo foi demonstrar como a Teoria Fundamentada em Dados (TFD) pode ser aplicada em uma pesquisa no campo da educação superior da qual buscou explorar os temas em evidências sobre a universidade na contemporaneidade. Assim, destacamos dois aspectos: o objetivo foi alcançado, uma vez que foi demonstrado como a TFD construtivista foi aplicada e o segundo aspecto foi a técnica utilizando o My-Sae e o Gephi para responder as questões da pesquisa 
exploratória nas fases da TFD. Esses softwares possibilitaram a captura dos dados e dos códigos dando uma margem de segurança no que se refere à qualidade e veracidade dos dados.

As discussões conceituais e metodológicas, além de atender ao objetivo da pesquisa, demonstraram a importância de estudos sobre a educação superior visto que se trata de uma área com vastas possibilidades para investigação diante da multiplicidade de temas emergentes. Com características multidimensionais e multifuncionais, a universidade atende aos diferentes paradigmas sociais, políticos, históricos, culturais e principalmente econômico. E neste diálogo com a sociedade ela é desafiada a atender as suas demandas fazendo emergir dessa interação cotidianamente novos dados, novos fenômenos.

A Teoria Fundamentada é uma metodologia de pesquisa sistemática, flexível, estruturada em várias fases interdependentes e uma dinâmica circular de comparações constantes dos dados. O seu resultado tende a ser útil, aplicável, inédito visto que as complexidades do contexto devem ser incorporadas à compreensão do fenômeno analisado a partir da base empírica. Pode-se concluir que trata-se de uma metodologia trabalhosa e também dinâmica. As suas diretrizes e fases colocam o pesquisador em contato direto com os dados.

A TFD demonstrou ser útil se aplicada ao campo da educação, pois a sua finalidade é propositiva, reflexiva e sistemática. Dessa forma, sugere-se para novos estudos, a ampliação da pesquisa bibliográfica com uso dessa metodologia; a realização de pesquisas empíricas com análise documental em profundidade, com uso de softwares ou não, uma vez que essas duas abordagens ainda são pouco utilizadas no campo das Ciências Sociais e educacional. Sugere-se ainda a publicação e difusão desta metodologia no Brasil, visto que é uma metodologia bem difundida internacionalmente e muito eficaz na área de saúde e administração.

\section{Referências}

Amado, J. (2017). Manual de investigação Científica. Imprensa da Universidade de Coimbra. (3a ed.), https://www.google.com.br/books/edition/Manual_de_I nvestiga\%C3\%A7\%C3\%A3o_Qualitativa_em/-LktDwAAQBAJ?hl=pt-BR\&gbpv=1\&printsec=frontcover

Bandeira-De-Mello, R., \& Cunha, C. (2003). Operacionalizando o método da Grounded Theory nas pesquisas em estratégia: técnicas e procedimentos de análise com apoio do software ATLAS/TI. Anais do Encontro de Estudos em Estratégia - ANPAD, 1-18.

Charmaz, K., (2009). A Construção da Teoria Fundamentada: guia prático para análise qualitativa. Tradução: Joice Elias Costa. Artmed.

Charmaz, K., (2014). Construtivism Grounded Theory. Sage Publications Ltd. London EC1Y SP. Firs Edition Published 2006.

Charmaz, K., (2017). Constructivist grounded theory The Journal of Positive Psychology, 12 (3), 299-300 http://dx.doi.org/10.1080/17439760.2016.1262612.

Canan, S. R., \& Sudbrack, E. M. (2018) A universidade brasileira e as políticas de educação superior no território Íbero-americano: avançamos? Holos, 34 (2). http://www2.ifrn.edu.br/ojs/index.php/HOLOS/rt/captureCite/5429/0. http://doi.org/15628/holos.2018.5429.

Carvalho, L. O. R., Duarte, F. R., Menezes, A. H. N.; \& Souza T., E., S., et al..(2019) Metodologia científica: teoria e aplicação na educação a distância / Petrolina-PE, 83 p. https://portais.univasf.edu.br/noticias/univasf-publica-livro-digital-sobre-metodologia-cientifica-voltada-para-educacao-a-distancia/livrode-metodologia-cientifica.pdf

C., V. M., \& Tonelli, M. J. (2020). Grounded Theory: Passo a passo e questões metodológicas na prática. Revista de Administração Mackenzie, 21(5), 1-29. http://doi.10.1590/1678-6971/eRAMG200130

Denzin, N. K. \& Lincoln, Y S. et al. O planejamento da pesquisa qualitativa: Teorias e abordagens. (2a ed.). Artmed e Bookman.

Fialho N. H. (2011). Políticas de Educação Superior, impactos nos processos de ensinar e aprender. EDUFBA.

Gill. A. C., (2006). Métodos e Técnicas de Pesquisa Social. (6a ed.), Atlas.

Gonçalves, W. A.; (2016). Método Grounded Theory: um norte teórico segundo o estado-da-arte do último biênio. Revista Conbrad. 1(2), 117-134.

Lobato, P. J., Freitas, E. M. J. \& Saba, H. P. C. (2018); Semantic Analysis Expert. 2019 Patente: Programa de Computador. Número do registro: BR512019000987-8, Registro: 21/05/2019. INPI - Instituto Nacional da Propriedade Industrial.

Maués, O. C. (2019), Ensino superior na ótica dos organismos internacionais. Educar em Revista, Curitiba, Brasil, 35(75), 13-30.

Morosini, M. \& Fernandes (2011). A Universidade no Brasil. Concepções e Modelos. Distrito Federal, Brasília. INEP.

Nakayama, K. M., Nunes, C. S., Oliveira, P. C., Torres, M. K. L. (2014). Revista Brasileira de Pós-Graduação RBPG, 11(24), 485-510. 
Research, Society and Development, v. 10, n. 5, e48710515026, 2021

(CC BY 4.0) | ISSN 2525-3409 | DOI: http://dx.doi.org/10.33448/rsd-v10i5.15026

Nakayama, K. M., \& Oliveira, P. C., (2018). Revista Pesquisa Qualitativa. 6(12), 572-594.

Oliveira, M. F., (2011), Metodologia Científica: um manual para a realização de pesquisas em Administração. Catalão. UFG, 72 p. Manual (pós-graduação) Universidade Federal de Goiás.

Prigol, E. L.\& Behrens, M. A. (2019), Educação \& Realidade, 44 (3), e84611.

Santos. B. (2010). A universidade no século 21: para uma reforma democrática e emancipatória da universidade. Cortez, 2005. (2a ed.).

Silveira, C. F. \& Costa, S. A. H. (2018) Ensino Aprendizagem para Além da Sala: Reflexões e experiências na área de empreendedorismo e eletrônica digital no Instituto Federal da Bahia. In: Lima J. P. A.\& Costa, G. E. B. (Auto)nomia: atuação do educador em diferentes espaços. CRV. 246 p.

Silveira, C. F. Nascimento, J. B. do, \& Saba, H. P. C., (2020). A theoretical-practical view of the diffusion of innovation and Intellectual Property. Research, Society and Development, 9(11), e71491110440. https://doi.org/10.33448/rsd-v9i11.10440

Strauss e Corbin (2008). Pesquisa Qualitativa: Técnicas e procedimentos para o desenvolvimento da teoria fundamentada. (2a ed.), Artmed.

Tarozzi, M. (2011) O que é a Grounded Theory: metodologia de pesquisa e de teoria fundamentada nos dados. Vozes. 